\title{
ASPECTOS MINERALÓGICOS, FÍSICOS E QUÍMICOS NA FLOTAÇÃO CATIÔNICA INVERSA DE MINÉRIOS DE FERRO DE BAIXOS TEORES, DO QUADRILÁTERO FERRÍFERO-MG
}

Rosa Malena Fernandes Lima ' Gilmara Mendonça Lopes ${ }^{2}$

Carlos de Figueiredo Gontijo ${ }^{3}$

\section{Resumo}

Neste artigo é efetuada uma discussão sobre a influência das características mineralógicas, físicas e químicas de quatro tipologias de minério de ferro de baixo teor, do Quadrilátero Ferrífero-MG, sobre o desempenho da flotação catiônica inversa para concentrá-los. Para as três tipologias de minérios de menores teores de Fe, foram obtidos concentrados com teores de $\mathrm{Fe}$ e de $\mathrm{SiO}_{2}$ com especificações de standard sinter feed. Os valores dos índices de seletividade

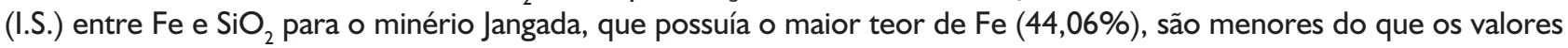
obtidos para os demais minérios, provavelmente devido ao menor grau de liberação do quartzo desse minério em relação aos outros minérios estudados.

Palavras-chaves: Caracterização tecnológica; Flotação; Minério de ferro.

\section{MINERALOGICAL, PHYSICAL AND CHEMICAL ASPECTS ON CATIONIC INVERSE FLOTATION OF LOW- GRADE IRON ORES FROM QUADRILATERO FERRÍFERO-MG}

\begin{abstract}
In this paper is carried out a discussion about the influence of mineralogical, physical and chemical characteristics of four low-grade iron ores from Quadrilátero Ferrífero-MG on the performance of inverse cationic flotation to concentrate them. For the three iron ore typologies of lowest iron grade, it was obtained concentrates with $\mathrm{Fe}$ and $\mathrm{SiO}_{2}$ grades with standard sinter feed specifications. The values of selectivity indices (S.I.) between $\mathrm{Fe}$ and $\mathrm{SiO}_{2}$ for Jangada ore, which had higher Fe content (44.04\%), are smaller than the values obtained for the others ores, probably due the smaller liberation degree of quartz of this ore compared with the others studied ores.
\end{abstract}

Key words: Technological characterization; Flotation; Iron ore.

\section{INTRODUÇÃO}

Aspectos geológicos, em particular a mineralogia e a gênese, de minérios de ferro têm papel importante tanto para o entendimento quanto para a escolha do método mais adequado para beneficiá-los. ${ }^{(1,2)}$

Upadhyay et al.,(2) após estudos de caracterização mineralógica, granulométrica e química de amostras de minérios de ferro da região nordeste da Índia classificou-os em maciço duro de alto teor, pulverulento azul de alto teor, minério friável tipo flaky, minério laterítico e minério goethítico. Posteriormente, os pesquisadores constataram que o beneficiamento dos minérios maciços e laminados hematíticos pode ser efetuado por fragmentação e classificação granulométrica. Para o minério puverulento azul de alto teor, faz-se necessário somente a utilização de peneiramento. Para as demais tipologias de minérios, que possuem baixo teor, foram escolhidos métodos de concentração, que levaram em consideração a sua assembléia mineralógica. Para granulometrias mais grosseiras dos

\footnotetext{
' Doutora, Professora Associada II, Programa de Pós-Graduação em Engenharia Mineral, Departamento de Engenharia de Minas, Universidade Federal de Ouro Preto, Campus Universitário Morro do Cruzeiro, s/n, Cep 354000-000, Ouro Preto, MG, Brasil. E-mail: rosa@demin.ufop.br ${ }^{2}$ MSc, Doutoranda do Curso de Pós-Graduação em Engenharia Metalúrgica e de Materiais, Universidade Federal de Minas Gerais, Av. Presidente Antônio Carlos, 6627, Campus da UFMG, Pampulha, Escola de Engenharia, Bloco II, Sala 2230, Cep 31270-90I, Belo Horizonte, MG, Brasil. E-mail: gill203@gmail.com

${ }^{3}$ PhD, Especialista em Processo Mineral, Vale S.A., Rua Paraíba, I I22, II andar, Cep 30130-I4I, Savassi, Belo Horizonte, MG, Brasil.

E-mai: carlos.gontijo@vale.com
} 
minérios de teores médios, a jigagem foi mais eficiente. No caso das frações finas e das lamas, ciclonagem, separação magnética, meio denso e algumas técnicas avançadas como flotação em coluna e separação multigravítica, foram efetivas na concentração dos mesmos.

Segundo Araújo et al.,"(1) a escolha da técnica de concentração (concentração gravítica, separação magnética de baixa e alta intensidade, flotação) para as frações granulométricas finas de minérios brasileiros, sinter feed e pellet feed, é efetuada levando-se em consideração a proporção dos minerais-minérios de ferro e dos minerais de ganga presentes nos mesmos. Para sinter feed, empregam-se concentração magnética, concentração gravítica (meio denso, espirais e jigagem). A concentração magnética de alta intensidade não é recomendada para minérios em que a magnetita e o quartzo são os minerais predominantes. A flotação inversa catiônica de pellet feed é fortemente recomendada para minérios, cujo mineral-minério predominante é a hematita e ganga constituída principalmente pelo quartzo com baixa proporção de minerais de alumínio. Ela é recomendada também para minérios, cujos minerais portadores de ferro predominantes são a magnetita e geothita associadas ao quartzo com baixas proporções de alumino-silicatos.

Em circuitos industriais de beneficiamento de minério de ferro, que empregam concentração magnética de alta intensidade, faz-se necessária uma etapa inicial de desbaste em equipamentos de baixo campo magnético $(<2.000 \mathrm{G})$ para minérios de ferro com proporção volumétrica de $30 \%$ de magnetita. Para propoção volumétrica de magnetita entre $5 \%$ e $30 \%$, a etapa de desbaste é efetuada por separação magnética de médio campo $(2.000 \mathrm{G}$ a $9.000 \mathrm{G}){ }^{(3)}$

A perda de recuperação na flotação de minérios, contendo hematita especular e hematita martítica hidrotermal finas, deve-se a dois fatores: granulometria e hábito cristalino. ${ }^{(1,4)}$ Segundo Santos e Brandão, ${ }^{(5)}$ tanto a hematita martítica quanto a goethita presentes em amostras de minério de ferro de diferentes frentes de lavra da Mina de Alegria contribuem para o aumento da área superficial específica dos concentrados obtidos, sendo que a goethita terrosa é responsável pelo aumento de finos durante o processamento mineral.

Neste artigo é analisada a influência de aspéctos mineralógicos, físicos e químicos na flotação inversa catiônica de quatro amostras de minério de ferro de baixo teor do Quadrilátero Ferrífero - MG.

\section{MATERIAIS E MÉTODOS}

Os estudos de caracterização tecnológica das quatro amostras de minério de ferro Jangada, João Pereira, Fábrica Nova e Serra Serpentina), fornecidas pela Vale S.A., com granulometria adequada para os ensaios de flotação, constaram de: análise mineralógica, análise granulométrica, análise química por fluorescência de raios X (Rigaku, modelo 3550), além de determinação de perda por calcinação (PPC), do peso específico, da superfície específica e da porosidade.

As semiquantificações mineralógicas das quatro amostras foram efetuadas por contagem de pontos, usando microscopia óptica de luz refletida. As análises granulométricas foram efetuadas por peneiramento a úmido e/ou combinado até a granulometria de $38 \mu \mathrm{m}$, usando a série Tyler de peneiras, e pelo granulômetro a laser (CILAs 1064) para a fração abaixo de $38 \mu \mathrm{m}$. Os pesos específicos das amostras foram determinados por picnometria a gás (Multipycnometer 1000). Enquanto que as áreas superficiais foram efetuadas pelo analisador de área superficial BET QuantaChrome - modelo Nova I200e.

Os ensaios de flotação em escala de bancada foram efetuados pela utilização de planejamento fatorial de experimentos $\left(2^{2}\right)$ com réplica, cujas variáveis estudadas foram dosagem de amina EDA da Clariant $(75 \mathrm{~g} / \mathrm{t}$ e $150 \mathrm{~g} / \mathrm{t}$ ) e dosagem de amido de milho da Santa Amália $(200 \mathrm{~g} / \mathrm{t} \mathrm{e} 400 \mathrm{~g} / \mathrm{t})$. Nesses ensaios foram fixados o valor de $\mathrm{pH}$ em 10,5, porcentagem de sólidos em $45 \%$ em peso, rotação da célula de flotação (CIMAQ com cuba de I,5 L) em I.200 RPM, tempo de condicionamento com amido e amina em 5 minutos e 3 minutos, respectivamente. As variáveis respostas analisadas, utilizando o software Minitab 15, foram: recuperação metalúrgica de Fe, teores de $\mathrm{Fe}$ e de $\mathrm{SiO}_{2}$ no concentrado e índice de seletividade de Gaudin (I.S.) entre o $\mathrm{Fe}$ e o $\mathrm{SiO}_{2}$.

\section{RESULTADOS E DISCUSSÃO}

Levando-se em consideração as técnicas de concentração de minérios de ferro de baixo teor, pode-se inferir através das proporções dos minerais presentes nas amostras estudadas (Tabela I) que, para concentração magnética de alta intensidade dos minérios Jangada e João Pereira, faz-se necessária uma etapa de desbaste com campo magnético de média intensidade para remoção da magnetita presente nas mesmas, conforme reportado por Queiroz e Brandão.(3) Como os minerais hematita e quartzo presentes em todas as amostras possuem maiores proporções, a flotação catiônica inversa é altamente recomendada para concentrá-los. ${ }^{(1)}$ No entanto, a maior proporção de hematita especular e lamelar no minério Serra Serpentina, pode levar à menor recuperação de ferro, devido à dificuldade na depressão dos mesmos, ocasionada pela forma das partículas. ${ }^{(1,4)} \mathrm{O}$ menor grau de liberação do quartzo dos minerais de ferro observado no minério Jangada $(94,8 \%)$, em comparação com os demais minérios (100\%), pode levar à depressão das partículas mistas com o consequente aumento do teor de $\mathrm{SiO}_{2}$ e diminuição do teor de Fe nos concentrados obtidos para essa tipologia de minério. 
Tabela I. Análise mineralógica semiquantitativa, porosidade e grau de liberação do quartzo das amostras de minério de ferro, determinados por microscopia óptica

\begin{tabular}{|c|c|c|c|c|}
\hline \multirow{2}{*}{$\begin{array}{c}\text { Minerais } \\
\text { identificados (\%) }\end{array}$} & \multicolumn{4}{|c|}{ Minério } \\
\hline & Jangada & $\begin{array}{l}\text { João } \\
\text { Pereira }\end{array}$ & $\begin{array}{c}\text { Fábrica } \\
\text { Nova }\end{array}$ & $\begin{array}{c}\text { Serra } \\
\text { Serpentina }\end{array}$ \\
\hline Hematita especular & 0,61 & 0,03 & 0,19 & 19,60 \\
\hline Hematita lamelar & 3,75 & 0,67 & 0,72 & 23,74 \\
\hline Hematita granular & $|3,0|$ & I I,40 & 4,10 & 10,95 \\
\hline Hematita sinuosa & 28,99 & 1,06 & 1,25 & 0,19 \\
\hline Hematita compacta & 46,36 & 13,17 & 6,26 & 54,48 \\
\hline Hematita martítica & 0,34 & 23,16 & 30,41 & - \\
\hline Magnetita & 13,07 & $\mathrm{II}, 76$ & 0,77 & - \\
\hline Goethita & 0,28 & 1,67 & 3,67 & $\mathrm{I}, 03$ \\
\hline Goethita terrosa & 0,42 & $\mathrm{I}, 84$ & 2,14 & 0,46 \\
\hline Quartzo livre & 37,25 & 47,65 & 56,09 & 43,39 \\
\hline Quartzo misto & 2,09 & - & 0,06 & - \\
\hline Caulinita & 0,03 & 0,13 & 0,13 & 0,09 \\
\hline Gbsita & 0,18 & 0,63 & 0,48 & 0,54 \\
\hline Poros & 12,75 & 7,93 & 12,50 & 4,38 \\
\hline $\begin{array}{l}\text { Grau de liberação } \\
\text { do quartzo }\end{array}$ & 94,70 & 100,00 & 99,89 & 100,00 \\
\hline
\end{tabular}

A porcentagem de finos, partículas menores do que $10 \mu \mathrm{m}$, varia de $3 \%$ (minério Serra Serpentina) a I $2 \%$ (minério João Pereira) (Figura I). A maior proporção de finos no minério João Pereira pode ocasionar o recobrimento das partículas de quartzo pelos finos de minerais de ferro (slime coating), que se reportariam para o produto concentrado e, dessa forma, ocasionaria aumento do teor de $\mathrm{SiO}_{2}$ no concentrado obtido.

Pela análise das composições químicas dos minérios estudados (Tabela 2), pode-se afirmar que o minério Jangada é o minério de maior teor dentre as amostras analisadas: teor de $\mathrm{Fe}$ e de $\mathrm{SiO}_{2}$ de $40,08 \%$ e 42, I8\%, respectivamente. $O$ minério Fábrica Nova é o mais pobre,

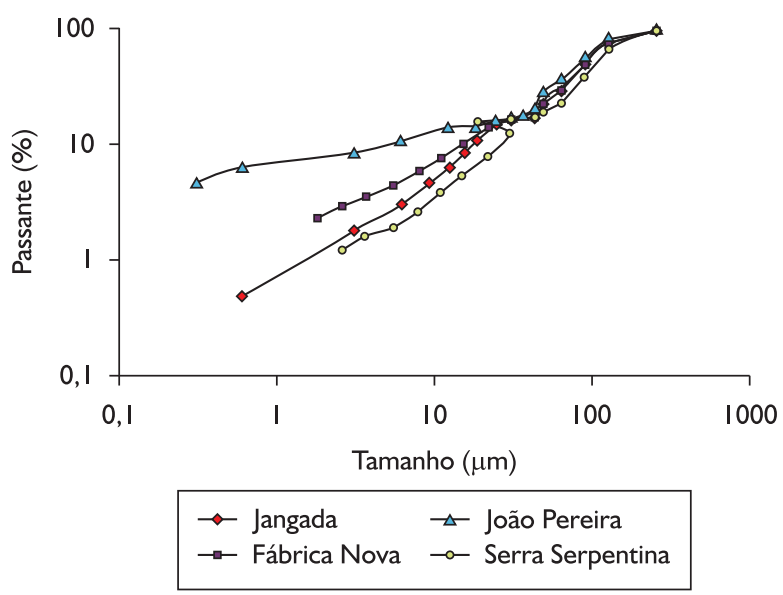

Figura I. Distribuição granulométrica das amostras de minério de ferro. com teor de $\mathrm{Fe}$ de $3 \mathrm{I}, 45 \%$ e de $\mathrm{SiO}_{2}$ igual a 52,35\%, e não há diferenças significativas entre os teores de $\mathrm{Fe}$ e $\mathrm{SiO}_{2}$ das amostras João Pereira $(33,94 \%$ e $50,65 \%)$ e Serra Serpentina (34,66\% e 49,04\%).

Pela Tabela 3 observa-se que os pesos específicos dos minérios variam de $3,4 \mathrm{~g} / \mathrm{cm}^{3}$ (Fábrica Nova) a $4 \mathrm{~g} / \mathrm{cm}^{3}$ (Jangada). Os valores encontrados estão coerentes com os resultados das composições químicas apresentadas na Tabela 2. O minério de maior teor de Fe (Jangada) possui - maior peso específico, pois o decréscimo do teor de ferro das amostras corresponde a uma diminuição em seus correspondentes pesos específicos. $O$ minério João Pereira possui a maior área superficial MultPoint BET $\left(7,24 \mathrm{l} \mathrm{m}^{2} / \mathrm{g}\right)$, seguido de Fábrica Nova $\left(3,945 \mathrm{~m}^{2} / \mathrm{g}\right)$. Coincidentemente, esses dois minérios possuem maiores valores de porosidade, $6,069 \times 10^{-3}$ e $4,082 \times 10^{-3} \mathrm{~cm}^{3} / \mathrm{g}$, respectivamente.

De uma maneira geral, o minério Jangada (Figura 2), apesar de possuir maior teor de Fe $(40,04 \%)$ e menor teor de $\mathrm{SiO}_{2}(42,18 \%)$ (Tabela I), teve o pior desempenho na flotação quando comparado com as outras amostras estudadas (Figuras 3, 4 e 5). O maior índice de seletividade $(5,4)$ entre o $\mathrm{Fe} \mathrm{e} \mathrm{o} \mathrm{SiO}_{2}$ foi obtido para a dosagem de $150 \mathrm{~g} / \mathrm{t}$ de

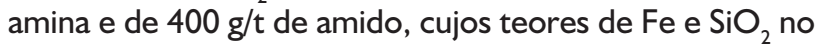
concentrado foram de $65 \%$ e de $6,5 \%$, respectivamente.

Tabela 2. Composição química e perda por calcinação (PPC) das amostras de minério de ferro

\begin{tabular}{lcccc}
\hline $\begin{array}{c}\text { Elemento } \\
\text { e/ou composto }\end{array}$ & Jangada & $\begin{array}{c}\text { João } \\
\text { Pereira }\end{array}$ & $\begin{array}{c}\text { Fábrica } \\
\text { Nova }\end{array}$ & $\begin{array}{c}\text { Serra } \\
\text { Serpentina }\end{array}$ \\
\hline $\mathrm{Fe}$ & 40,08 & 33,94 & 31,45 & 34,66 \\
$\mathrm{SiO}_{2}$ & 42,18 & 50,65 & 52,35 & 49,04 \\
$\mathrm{Al}_{2} \mathrm{O}_{3}$ & 0,25 & 0,46 & 0,63 & 0,93 \\
$\mathrm{TiO}_{2}$ & 0,016 & 0,033 & 0,023 & 0,036 \\
$\mathrm{CaO}$ & 0,022 & 0,023 & 0,020 & 0,023 \\
$\mathrm{MgO}$ & 0,003 & 0,091 & 0,039 & 0,085 \\
$\mathrm{Mn}$ & 0,020 & 0,030 & 0,162 & 0,04 \\
$\mathrm{P}$ & 0,014 & 0,027 & 0,034 & 0,017 \\
$\mathrm{PPC}$ & 0,17 & 0,22 & 1,88 & 0,59 \\
\hline
\end{tabular}

Tabela 3. Valores de peso específico, superfície específica e porosidade das amostras de minério de ferro

\begin{tabular}{lcccc}
\hline Minério & $\begin{array}{c}\text { Peso } \\
\text { específico } \\
\left(\mathbf{g} / \mathbf{c m}^{3}\right)\end{array}$ & \begin{tabular}{c} 
Superfície \\
específica \\
MP BET \\
\cline { 4 - 5 }$\left(\mathbf{m}^{2} / \mathbf{g}\right)$
\end{tabular} & $\begin{array}{c}\text { Volume total } \\
\left(\mathbf{c m}^{3} / \mathbf{g}\right)\end{array}$ & $\begin{array}{c}\text { Raio médio } \\
\text { dos poros } \\
\AA\end{array}$ \\
\hline Jangada & 4,0385 & 1,520 & $2,559 \times 10^{-3}$ & $3,367 \times 10^{1}$ \\
\hline $\begin{array}{l}\text { João } \\
\text { Pereira }\end{array}$ & 3,6340 & 7,241 & $6,069 \times 10^{-3}$ & 8,828 \\
\hline $\begin{array}{l}\text { Fábrica } \\
\text { Nova }\end{array}$ & 3,4015 & 3,945 & $4,082 \times 10^{-3}$ & $1,897 \times 10^{1}$ \\
\hline $\begin{array}{l}\text { Serra } \\
\text { Serpentina }\end{array}$ & 3,7100 & 1,782 & $1,898 \times 10^{-3}$ & $1,658 \times 10^{-1}$ \\
\hline
\end{tabular}

MP BET - MultPoint BET. 

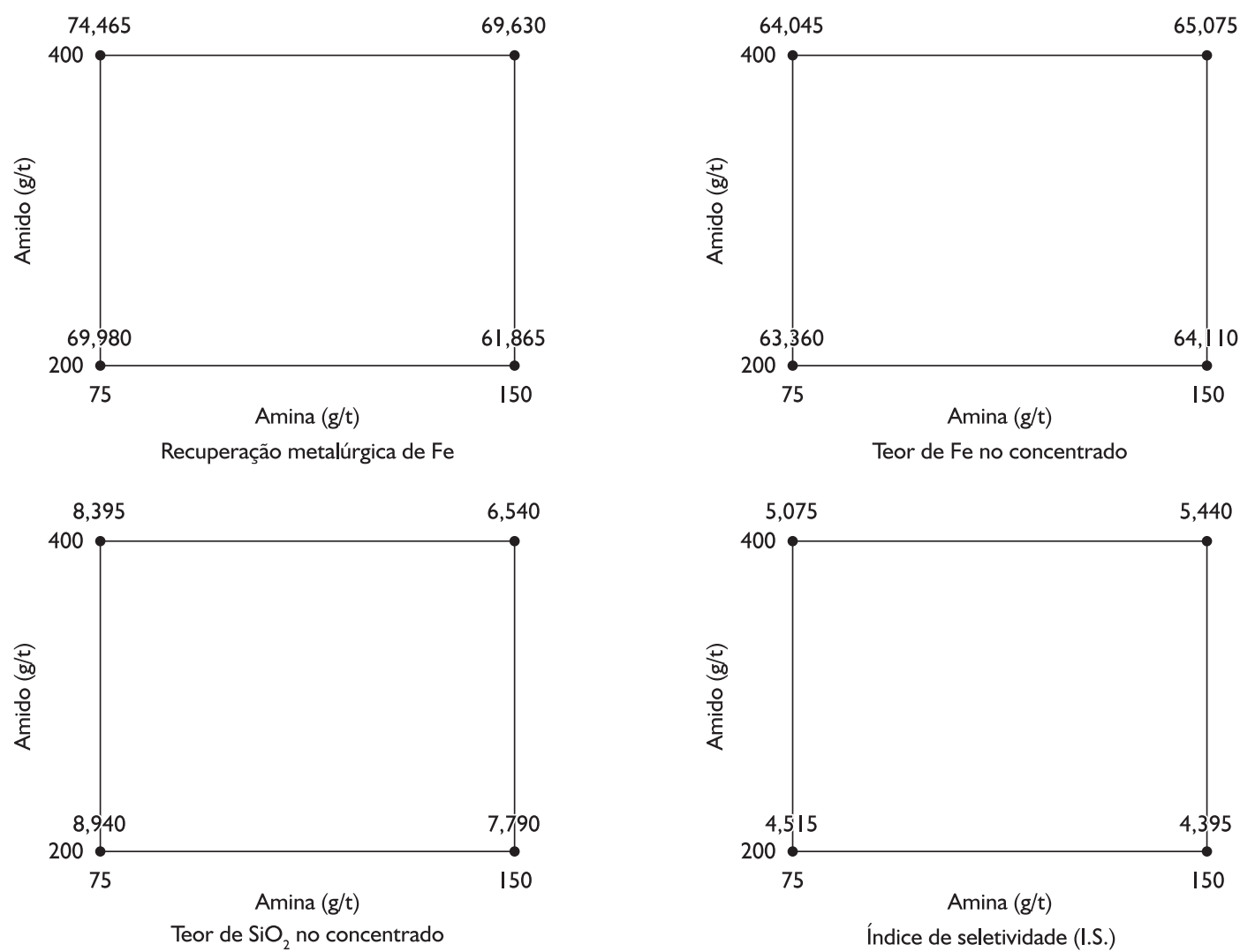

Figura 2. Influência da dosagem de amina e amido na flotação do minério Jangada.

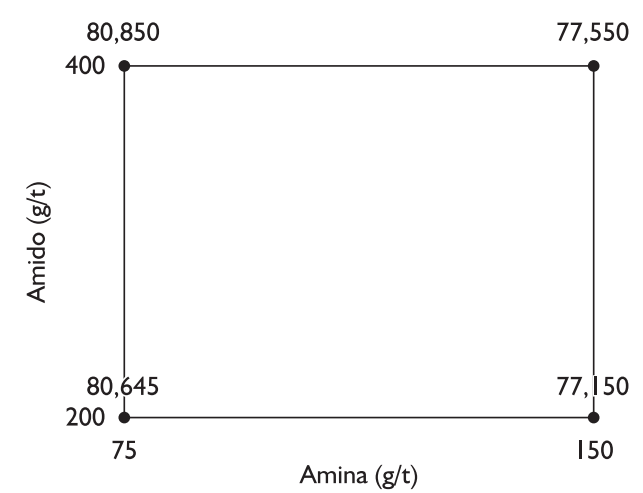

Recuperação metalúrgica de $\mathrm{Fe}$

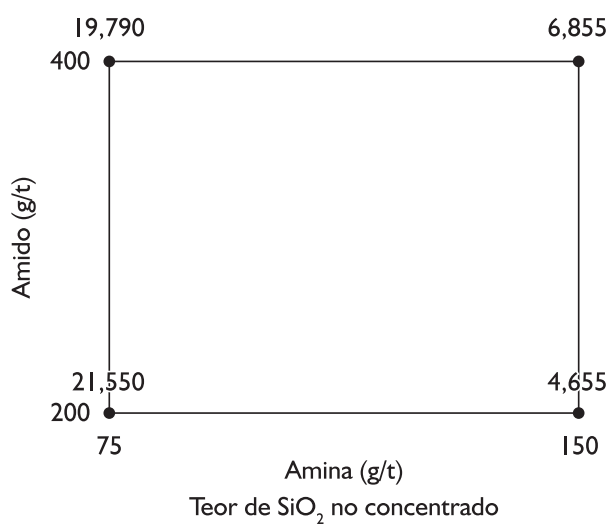

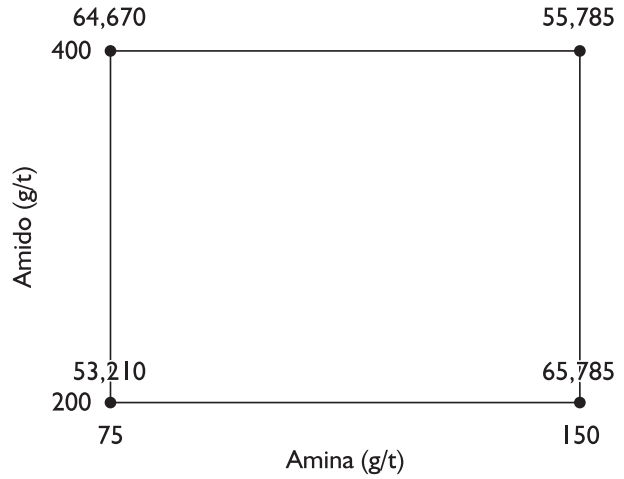

Teor de Fe no concentrado

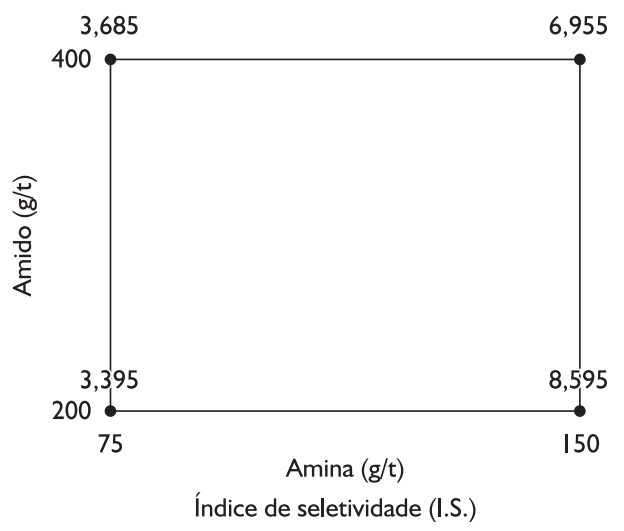

Figura 3. Influência da dosagem de amina e amido na flotação do minério João Pereira. 

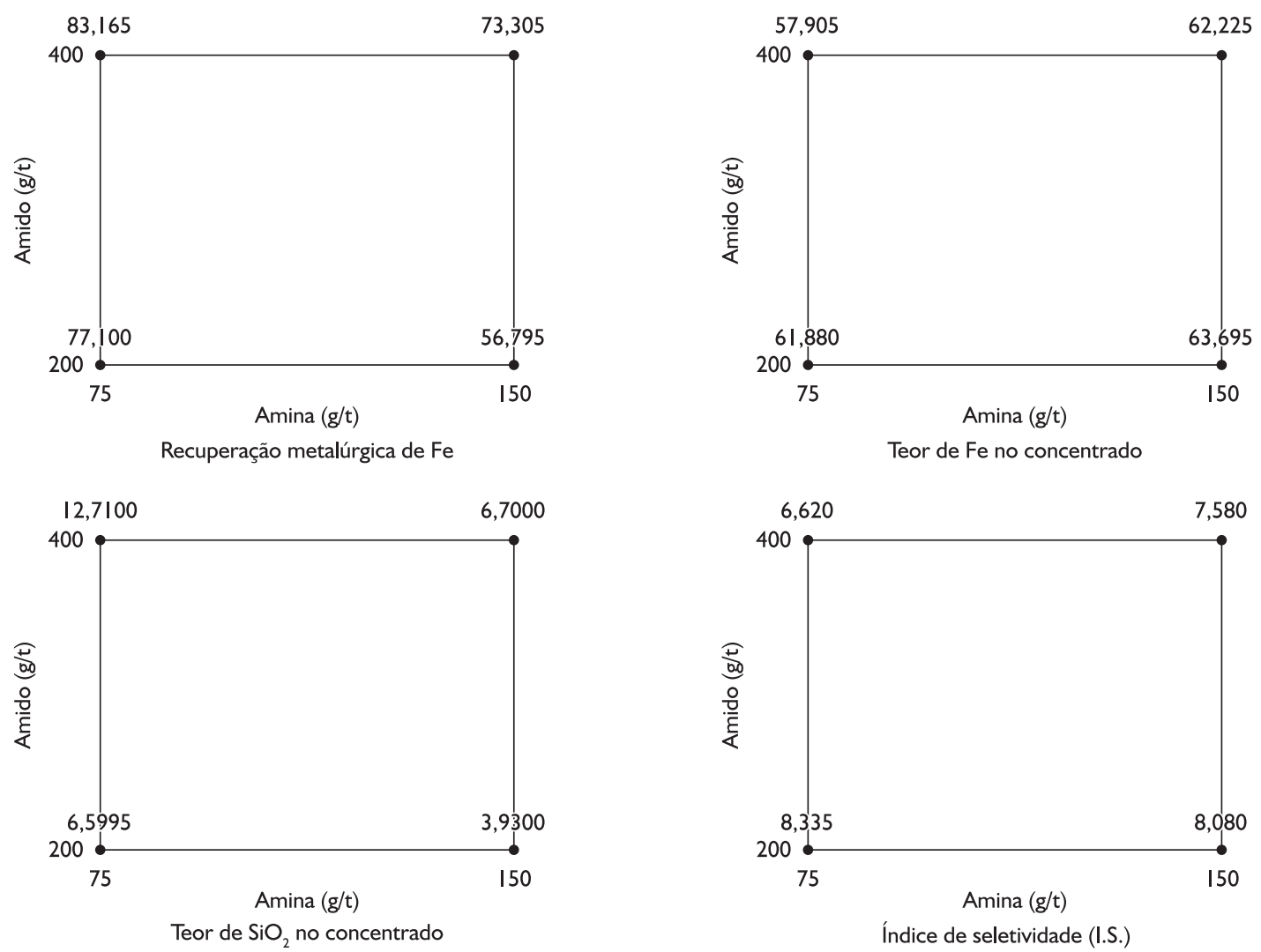

Figura 4. Influência da dosagem de amina e amido na flotação do minério Fábrica Nova.
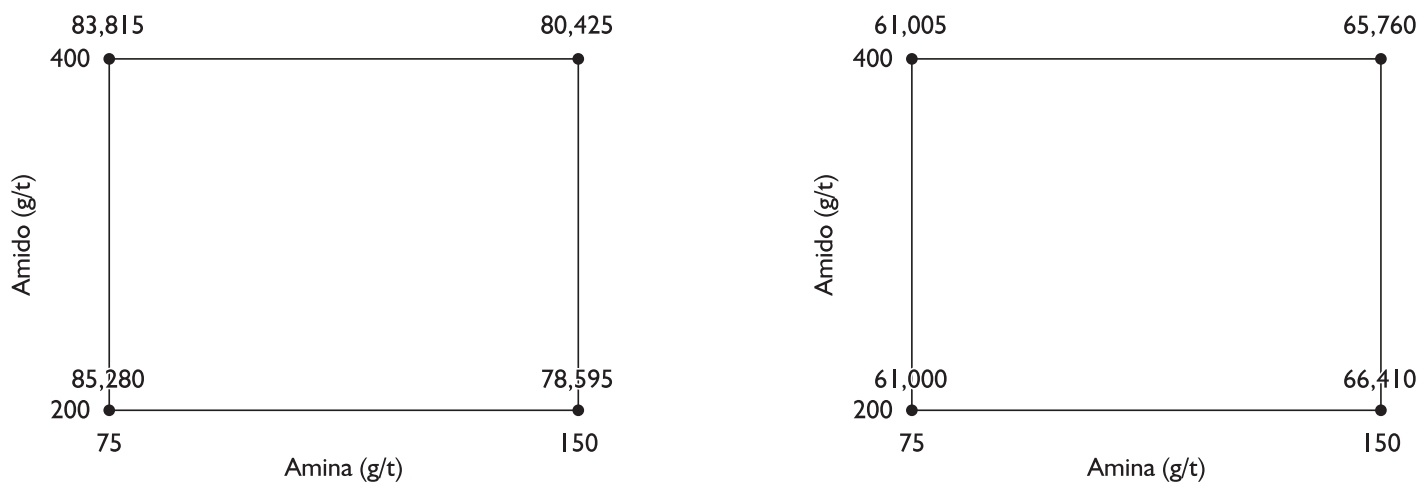

Recuperação metalúrgica de $\mathrm{Fe}$
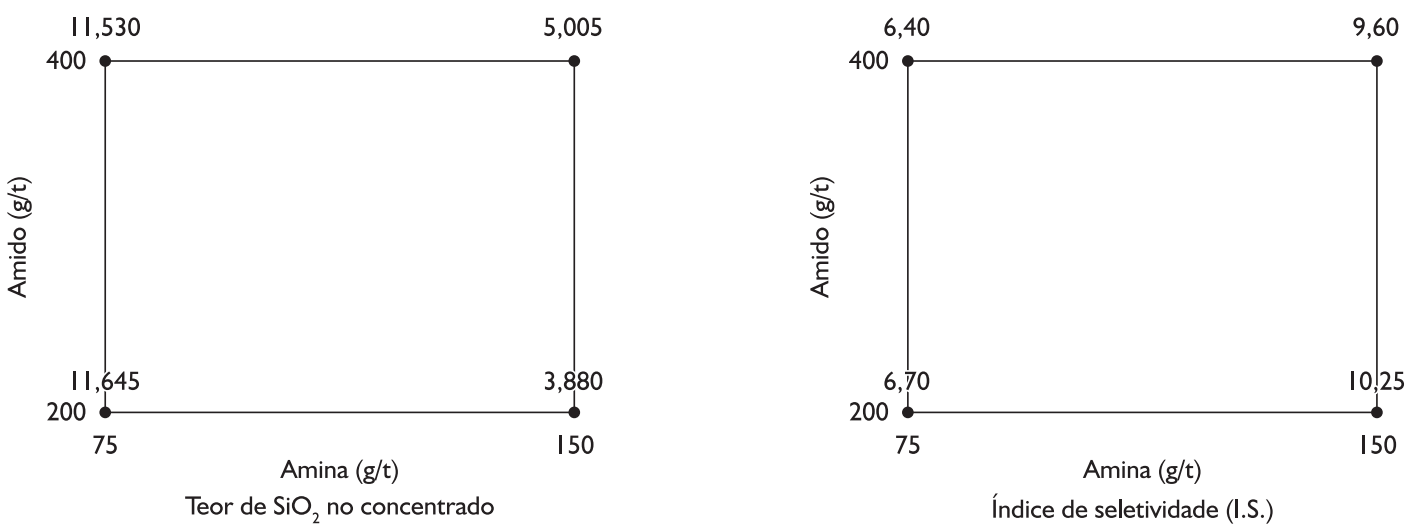

Figura 5. Influência da dosagem de amina e amido na flotação do minério Serra Serpentina. 
Esse comportamento pode estar relacionado com o menor grau de liberação dos minerais de quartzo desse minério $(94,8 \%)$ em relação aos demais minérios (100\%). Serra Serpentina foi o minério em que se obteve maior recuperação metalúrgica de $\mathrm{Fe}$, ultrapassando $85 \%$, apesar do mesmo conter a maior proporção de hematita especularítica, cujas partículas poderiam ser arrastadas para o rejeito, devido à dificuldade em deprimi-las em função da forma das mesmas. ${ }^{(4,5)}$ Porém, esse comportamento está coerente com a mineralogia do minério, pois ele também possui a maior proporção de hematita compacta $(54,48 \%)$ em relação aos demais. Para as dosagens de $150 \mathrm{~g} / \mathrm{t}$ de amina e $200 \mathrm{~g} / \mathrm{t}$ de amido, as recuperações metalúrgicas de Fe (Figuras 3, 4 e 5) foram maiores para o minério Serra Serpentina $(78,6 \%)$, seguido pelo minério João Pereira $(77,15 \%)$ e Fábrica Nova $(56,8 \%)$. Para essas dosagens foram obtidos maiores teores de $\mathrm{Fe}$ e menores teores de $\mathrm{SiO}_{2}$ nos concentrados, bem como maiores índices de seletividade entre o $\mathrm{Fe}$ e $\circ \mathrm{SiO}_{2}$ para o minério Serra Serpentina $(10,25)$, seguido do minério João Pereira $(8,6)$ e Fábrica Nova $(8,1)$.

Há de salientar que os teores de $\mathrm{SiO}_{2}$ e Fe nos concentrados obtidos, exceto o teor de Fe do minério Fábrica Nova (máximo de 63,7\%), adequam-se às especificações do produto standart sinter feed $\left(\mathrm{SiO}_{2}\right.$ entre $4 \%$ e
6\% e Fe de 64,5\%).(6) Pode-se afirmar que, embora essas três tipologias de minérios possuam composições mineralógicas e microtextura distintas (diferentes proporções de hematita lamelar, granular, sinuosa, compacta e martítica) e no caso da presença de II,76\% de magnetita no minério João Pereira, não levou a diferenças significativas em termos de teores de $\mathrm{SiO}_{2}$ e de Fe nos concentrados obtidos.

\section{CONCLUSÃO}

Nos ensaios de flotação catiônica inversa das amostras de minério de ferro de baixo teor do Quadrilátero Ferrífero-MG foram obtidos concentrados rougher com especificaçães de standard sinter feed, exceto para o minério Jangada (teor de $40,08 \%$ de $\mathrm{Fe}$ ), que teve o pior desempenho dentre os minérios estudados, devido à recuperação de partículas mistas de quartzo e minerais de ferro.

\section{Agradecimentos}

Os autores agradecem à Fapemig, a Capes e à Vale S.A.

\section{REFERÊNCIAS}

I ARAÚJO, A. C. et al. Ore mineralogy and its relevance for selection of concentration methods in processing of Brazilian iron ores. Mineral Processing and Extractive Metallurgy, v. I I2, n. I, p. C54-C64, Apr. 2003. http://dx.doi. org/I0.1I79/0371955032250II439

2 UPADHYAY, R. K. et al. Relevance of geological aspects and ore mineralogy in selecting beneficiation methods for processing of eastern Indian iron ores. Mineral Processing and Extractive Metallurgy, v. I I8, n. I, p. 49-59, Nov. 2009.

3 QUEIROZ, L. A.; BRANDÃO, P. R. G. Aspectos mineralógicos relacionados à concentração magnética de minério de ferro itabirítico. Metalurgia e Materiais, v. 65, n. I48, p. I48-54, abr. 2009.

4 LIBANEO, C. A. et al. Classificação mineralógica, textural e granulométrica de detalhe de minério de ferro (pellet feed) e suas implicações geometalúrgicas. In: SIMPÓSIO BRASILEIRO DE MINÉRIO DE FERRO, 3., 200 I, Ouro Preto, MG. Anais... São Paulo: ABM, 200I. p. 70-8.

5 SANTOS, L. D.; BRANDÃO, P. R. G. Variações mineralógicas e microestruturais em minérios de ferro do Quadrilátero Ferrífero, MG, e suas implicações no processamento mineral. In: SIMPÓSIO BRASILEIRO DE MINÉRIO DE FERRO, 4., 2003. Ouro Preto, MG. Anais... São Paulo: ABM, 2003. p. 674-82.

6 LIMA, R. M. F. Adsorção de amido e amina na superfície da hematita e do quartzo e sua influência na flotação. 1997.238 p. Tese (Doutorado em Engenharia Metalúrgica e de Minas) - Escola de Engenharia da Universidade Federal de Minas Gerais, Belo Horizonte, 1997.

Recebido em: 10/01/201 I

Aceito em: I2/04/20 I I 